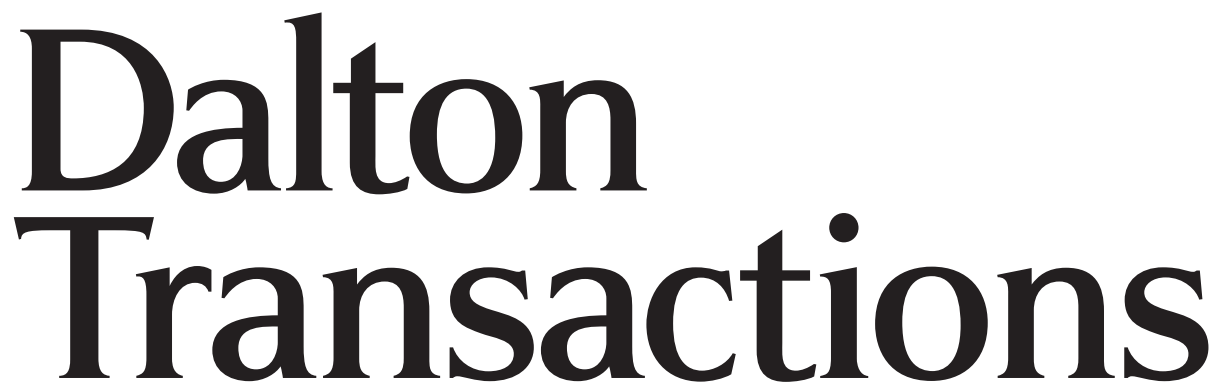

An international journal of inorganic chemistry

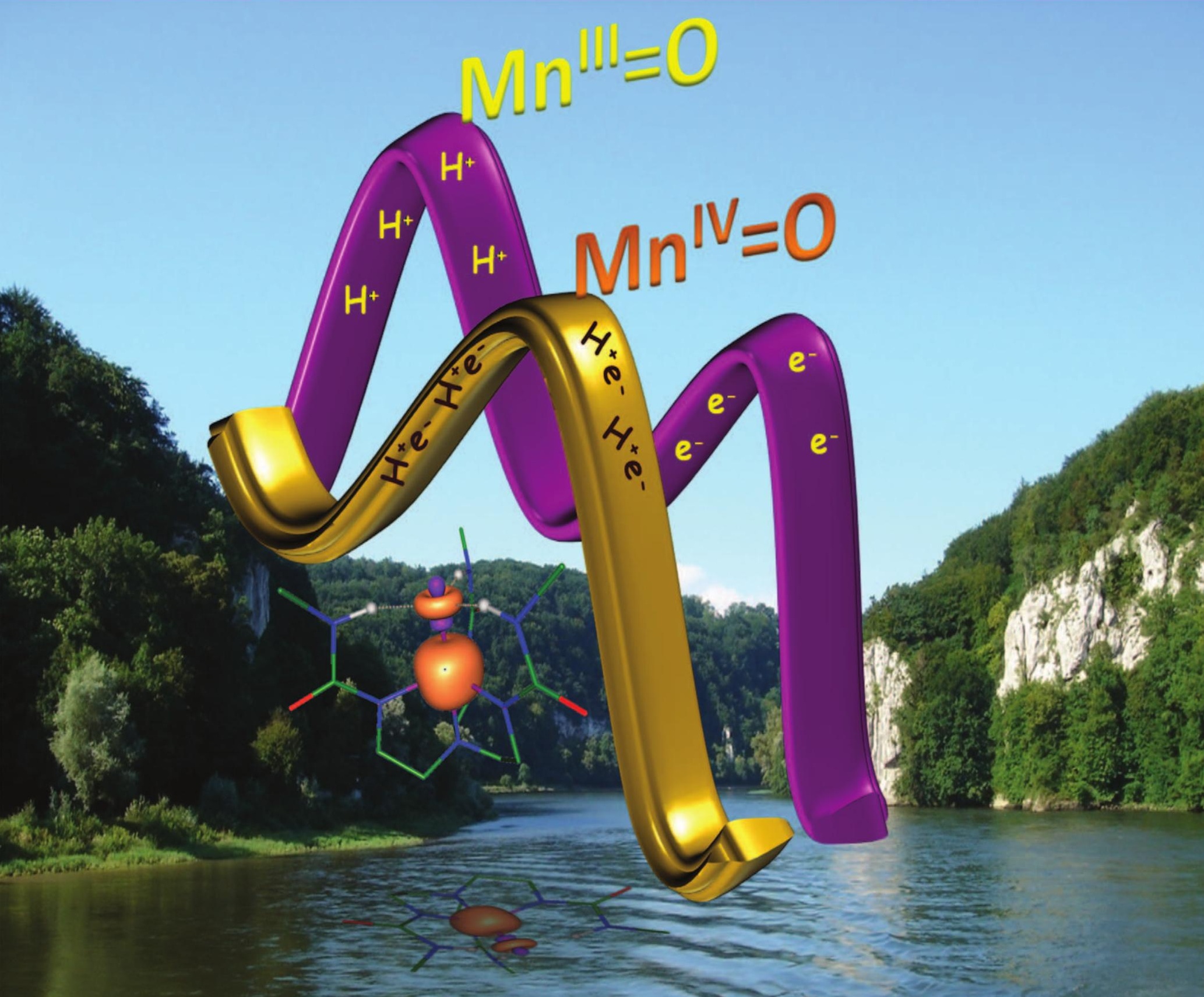

\title{
COVER ARTICLE
}

Rajaraman et al.

RSCPublishing

Theoretical studies on concerted versus two steps hydrogen atom transfer reaction by non-heme $\mathrm{Mn}^{\mathrm{IV} / \mathrm{III}}=\mathrm{O}$ complexes: how important is the oxo ligand

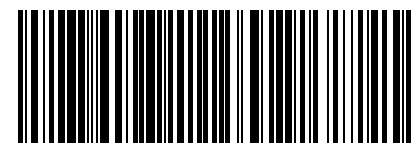




\title{
Dalton

\section{Theoretical studies on concerted versus two steps $\mathrm{Mn}^{\mathrm{IV} / \mathrm{III}}=\mathrm{O}$ complexes: how important is the oxo ligand basicity in the $\mathrm{C}-\mathrm{H}$ activation step?†\#} Cite this: Daton Trans, 2013,42,16518 hydrogen atom transfer reaction by non-heme

\author{
Madhavan Jaccob,§ Azaj Ansari, Bhawana Pandey and Gopalan Rajaraman*
}

High-valent metal-oxo complexes have been extensively studied over the years due to their intriguing properties and their abundant catalytic potential. The majority of the catalytic reactions performed by these metal-oxo complexes involves a $\mathrm{C}-\mathrm{H}$ activation step and extensive efforts over the years have been undertaken to understand the mechanistic aspects of this step. The $\mathrm{C}-\mathrm{H}$ activation by metal-oxo complexes proceeds via a hydrogen atom transfer reaction and this could happen by multiple pathways, (i) via a proton-transfer followed by an electron transfer (PT-ET), (ii) via an electron-transfer followed by a proton transfer (ET-PT), (iii) via a concerted proton-coupled electron transfer (PCET) mechanism. Identifying the right mechanism is a surging topic in this area and here using $\left[\mathrm{Mn}^{\prime \prime \prime} \mathrm{H}_{3} \mathrm{buea}(\mathrm{O})\right]^{2-}$ (1) and $\left[\mathrm{Mn}^{\mathrm{IV}} \mathrm{H}_{3} \text { buea }(\mathrm{O})\right]^{-}$(2) species (where $\mathrm{H}_{3}$ buea = tris $\left[\left(N^{\prime}\right.\right.$-tert-butylureaylato) $-N$-ethylene $]$ aminato) and its $\mathrm{C}-\mathrm{H}$ activation reaction with dihydroanthracene (DHA), we have explored the mechanism of hydrogen atom transfer reactions. The experimental kinetic data reported earlier (T. H. Parsell, M.-Y. Yang and A. S. Borovik, J. Am. Chem. Soc., 2009, 131, 2762) suggests that the mechanism between 1 and $\mathbf{2}$ is drastically different. By computing the transition states, reaction energies and by analyzing the wavefunction of the reactant and transitions states, we authenticate the proposal that the $\mathrm{Mn} \mathrm{n}^{\mathrm{III}}=\mathrm{O}$ undergoes a step wise PT-ET mechanism where as the $\mathrm{Mn}^{\mathrm{IV}}=\mathrm{O}$ species undergo a concerted PCET mechanism. Both the species pass through a $\left[\mathrm{Mn}^{\prime \prime \prime}-\mathrm{OH}\right]$ intermediate and the stability of this species hold the key to the difference in the reactivity. The electronic origin for the difference in reactivity is routed back to the strength and basicity of the $\mathrm{Mn}$-oxo bond and the computed results are in excellent agreement with the experimental results.

\section{www.rsc.org/dalton}

\section{Introduction}

Selective $\mathrm{C}-\mathrm{H}$ bond oxidative cleavage of aromatic/aliphatic hydrocarbons is one of the important synthetic transformations in enzymatic and industrial processes. Naturally, mononuclear non-heme high-valent ferryl-oxo species serve as an astonishing paradigm for the activation of $\mathrm{C}-\mathrm{H}$ bond in highly efficient and selective manner. ${ }^{1-4}$ Given the remarkable success of the oxidative potential of high-valent iron-oxo based model catalysts, many researchers were stimulated to

Department of Chemistry, Indian Institute of Technology Bombay, Mumbai, India.

E-mail: rajaraman@chem.iitb.ac.in; Fax: +91 022-25767152; Tel: +91 022-25767183 $\dagger$ Dedicated to Professor Peter Comba, University of Heidelberg, Germany, on the occasion of his $60^{\text {th }}$ birthday.

$\ddagger$ Electronic supplementary information (ESI) available: DFT computed structural parameters, spin density values and optimized structures of higher spin states. See DOI: 10.1039/c3dt52290c

$\S$ Present address: Department of Chemistry, Loyola College, Chennai-600034, Tamilnadu, India. target other metal based oxo complexes for achieving the $\mathrm{C}-\mathrm{H}$ bond oxidative cleavage. ${ }^{5-9}$ Among the reported other metal based biomimetic model complexes, the manganese based oxo complexes have shown to possess prominent catalytic ability towards the $\mathrm{C}-\mathrm{H}$ bond activation and $\mathrm{O}$-atoms transfer reactions when compared to ferryl-oxo species and also these model complexes are capable of mimicking the catalytic properties of lipooxygenase, cytochrome P450 and ironoxido reductase enzyme. ${ }^{10-13}$

The catalytic reactivity of the metal-oxo species towards the $\mathrm{C}-\mathrm{H}$ activation process is largely influenced by their redox properties. ${ }^{14-16}$ Besides some recent reports suggest that basicity of oxo ligands play a vital role in the rapid reactivity of manganese(Iv/v)-oxo complexes involving $\mathrm{C}-\mathrm{H}$ activation. ${ }^{17}$ The primacy of the basicity of oxo ligands was further legitimated by Borovik et al. through the $\mathrm{C}-\mathrm{H}$ bond cleavage ability of monomeric $\mathrm{Mn}(\mathrm{III} / \mathrm{IV})-$ oxo units with a tetradentate tripodal ligands $\left(\left[\mathrm{Mn}^{\mathrm{III} / \mathrm{IV}} \mathrm{H}_{3} \text { buea }(\mathrm{O})\right]^{2-/-}\right)\left(\mathrm{H}_{3}\right.$ buea $=\operatorname{tris}\left[\left(N^{\prime}\right.\right.$-tert-butylureaylato)- $N$-ethylene]aminato) having trigonal bipyramidal 
geometry. Their study clearly shows that the basicity of oxo ligands affect the kinetic aspects of the $\mathrm{C}-\mathrm{H}$ bond of activation. ${ }^{18}$ The KIE experiments reveal that $k_{\mathrm{H}}^{\mathrm{Mn}(\mathrm{O})} / k_{\mathrm{D}}^{\mathrm{Mn}(\mathrm{O})}$ values are twice as much for 2 compared to 1 (2.6vs. 6.8 for 1 and 2 respectively). Further a larger $\mathrm{p} K_{\mathrm{a}}$ measured for $\mathbf{1}$ compared to $\mathbf{2}$ lead to the suggestion of an anionic intermediate for $\mathbf{1}$ and a radical based intermediate for species 2 . Based on the KIE experiments and estimated activation barrier for the two species, a different mechanistic route has been proposed for $\mathrm{Mn}^{\mathrm{III}}=\mathrm{O}$ and $\mathrm{Mn}^{\mathrm{IV}}=\mathrm{O}$ species. The $\mathrm{C}-\mathrm{H}$ bond activation by $\left[\mathrm{Mn}^{\mathrm{III}} \mathrm{H}_{3} \text { buea }(\mathrm{O})\right]^{2-}$ (1) suggested to proceed through a two step mechanism, proton transfer followed by electron transfer whereas in $\left[\mathrm{Mn}^{\mathrm{IV}} \mathrm{H}_{3} \text { buea }(\mathrm{O})\right]^{-}$(2) the reaction proceeds in a single step, i.e. via proton-coupled electron transfer (PCET) step. This PCET mechanism is also suggested as the possible mechanism for iron and manganese lipooxygenase and cytochrome P450 enzymes. ${ }^{19-24}$ Further the mechanistic studies suggest that 1 follows anionic mechanism attributed to the strong basic character of the oxo group (larger $\mathrm{p} K_{\mathrm{a}}$ ) compared to species 2. Although the experimental study unfolds the differences in reactivity between 1 and 2 , the precise reason for the preferred choice of the mechanism by these oxidants is unclear and this aspect is important to establish connection between observed reactivity of these models to that of enzymes. In this regard, we have undertaken a theoretical study based on density functional method to specifically address the following issues. (i) Between $\mathrm{Mn}^{\mathrm{III}}=\mathrm{O}$ and $\mathrm{Mn}^{\mathrm{IV}}=\mathrm{O}$ species, which one is a stronger oxidant and why? (ii) What are the exact mechanisms by which $\mathbf{1}$ and 2 activate the $\mathrm{C}-\mathrm{H}$ bonds (PT-ET, ET-PT and PCET)? (iii) What are the electronic reasons behind the preferred choice of the mechanism?

\section{Computational details}

All the calculations were carried out using the Gaussian 09 suite of programs. ${ }^{25}$ The geometry optimizations have been performed with the B3LYP functional. ${ }^{26,27}$ The B3LYP has a proven track record of predicting the structures and the energetics accurately for such metal mediated catalytic reactions $^{28-30}$ (see ESI† for discussion on chosen methodology). The LACVP basis set comprising the LanL2DZ-Los Alamos effective core potential for the $\mathrm{Mn}^{31-34}$ and a $6-31 \mathrm{G}^{* 35}$ basis set for the other atoms have been employed for geometry optimization and the optimized geometries were then used to perform single point energy calculations using a TZVP basis set on all atoms. ${ }^{36,37}$ Solvation energies have been computed using PCM solvation model employing acetonitrile as the solvent. Frequency calculations were performed on the optimized structures at the B3LYP level to verify that they are minima on the potential-energy surface (PES) and also to obtain free energy corrections. The quoted DFT energies are the B3LYP/TZVP solvation energies incorporating free energies correction at the B3LYP/LACVP level, unless otherwise mentioned. The transition states were characterized by single imaginary frequency corresponding to the reaction coordinate and are verified by animating the frequency using visualization software such as Molden. ${ }^{38,39}$ The broken-symmetry approach available in Gaussian 09 is employed to aid smooth convergence in case of radical intermediates. ${ }^{40}$ The energy decomposition analysis (EDA) ${ }^{41-43}$ was performed at the same level of theory using AOMIX software. ${ }^{4-46}$

\section{Result and discussion}

\section{Mechanism of $\mathrm{C}-\mathrm{H}$ activation by $\mathrm{Mn}^{\mathrm{III}}=\mathrm{O}$ and $\mathrm{Mn}^{\mathrm{IV}}=\mathrm{O}$ species}

Here we have investigated the mechanistic aspects of the $\mathrm{C}-\mathrm{H}$ bond cleavage of dihydroanthracene (DHA) reaction by monomeric $\mathrm{Mn}^{\mathrm{III} / \mathrm{IV}}$-oxo complexes of tetradentate tripodal ligands with anionic nitrogen donors $\left(\mathrm{H}_{3}\right.$ buea) ligand using density functional methods. The proposed reaction mechanism involves two different pathways (anionic and radical) which are classified based on the type of intermediate formation (Scheme 1). In the anionic pathway, the monomeric oxomanganese species (1) $\left[\mathrm{Mn}^{\mathrm{III}}\left(\mathrm{H}_{3} \text { buea }\right)=\mathrm{O}\right]^{2-}$ abstract a proton from DHA leading to the formation of anionic monohydroanthracene (MHA) intermediate $\left(\mathbf{1}_{\text {intA }}\right)$ and $\left[\mathrm{Mn}^{\mathrm{III}}\left(\mathrm{H}_{3} \text { buea }\right)-\mathrm{OH}\right]^{-}$ species which further undergoes rapid electron transfer leading to the formation of $\left[\mathrm{Mn}^{\mathrm{II}}\left(\mathrm{H}_{3} \text { buea }\right)-\mathrm{OH}\right]^{2-}$ and MHA radical intermediate $\left(\mathbf{1}_{\text {intR }}\right)$. Further a second hydrogen abstraction (ts2) from the MHA leads to the formation of anthracene and $\left[\mathrm{Mn}^{\mathrm{II}}\left(\mathrm{H}_{3} \text { buea }\right)-\mathrm{OH}\right]^{2-}$ species. In the radical pathway, species $2\left(\left[\mathrm{Mn}^{\mathrm{IV}}\left(\mathrm{H}_{3} \text { buea }\right)=\mathrm{O}\right]^{-}\right)$undergoes PCET mechanism leading to the formation of MHA radical intermediate $\left(\mathbf{2}_{\text {intR }}\right)$ and $\left[\mathrm{Mn}^{\mathrm{III}}\left(\mathrm{H}_{3} \text { buea }\right)-\mathrm{OH}\right]^{1-}$ species. Subsequent hydrogen abstraction from the MHA radical intermediate lead to the formation of anthracene and $\left[\mathrm{Mn}^{\mathrm{III}}\left(\mathrm{H}_{3} \text { buea }\right)-\mathrm{OH}\right]^{-}$species. This adapted mechanism is consistent with the experimental observation. $^{18}$

We have computed all the possible mechanistic pathways for the $\mathrm{C}-\mathrm{H}$ bond activation reaction for both the oxidants 1 and 2 with DHA. Our B3LYP/TZVP calculations clearly show that both the oxidants possess a high spin $\left({ }^{5} \mathbf{1}\right.$ and $\left.{ }^{4} 2\right)$ ground state with excited $S=1$ and $S=1 / 2$ states lying at 127.8 and $81.3 \mathrm{~kJ} \mathrm{~mol}^{-1}$ higher in energy for $\mathbf{1}$ and 2 respectively

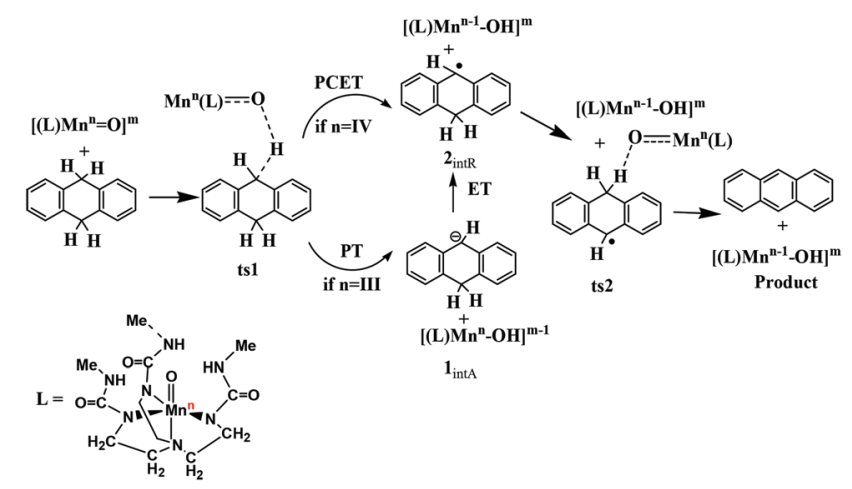

Scheme 1 Mechanistic scheme adopted for $\mathrm{C}-\mathrm{H}$ activation reaction involving monomeric oxomanganese(III/Iv) complexes. 


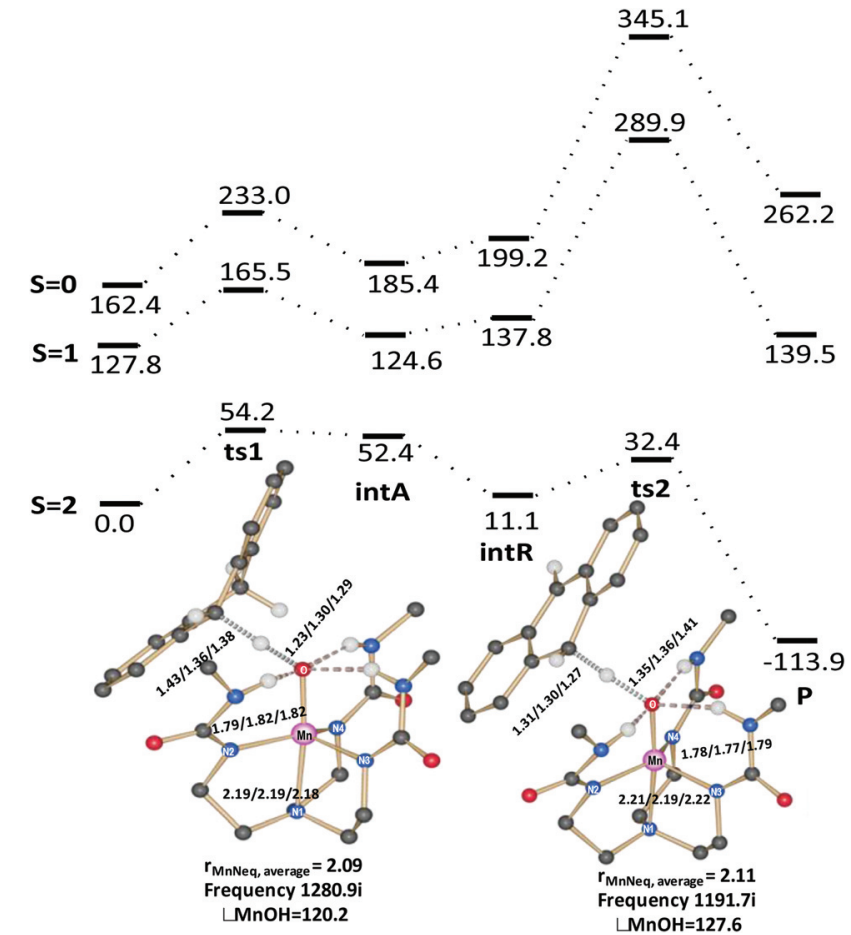

Fig. 1 Computed reaction profile of $\mathrm{C}-\mathrm{H}$ activation reaction involving $\mathrm{DHA}$ and species 1 .

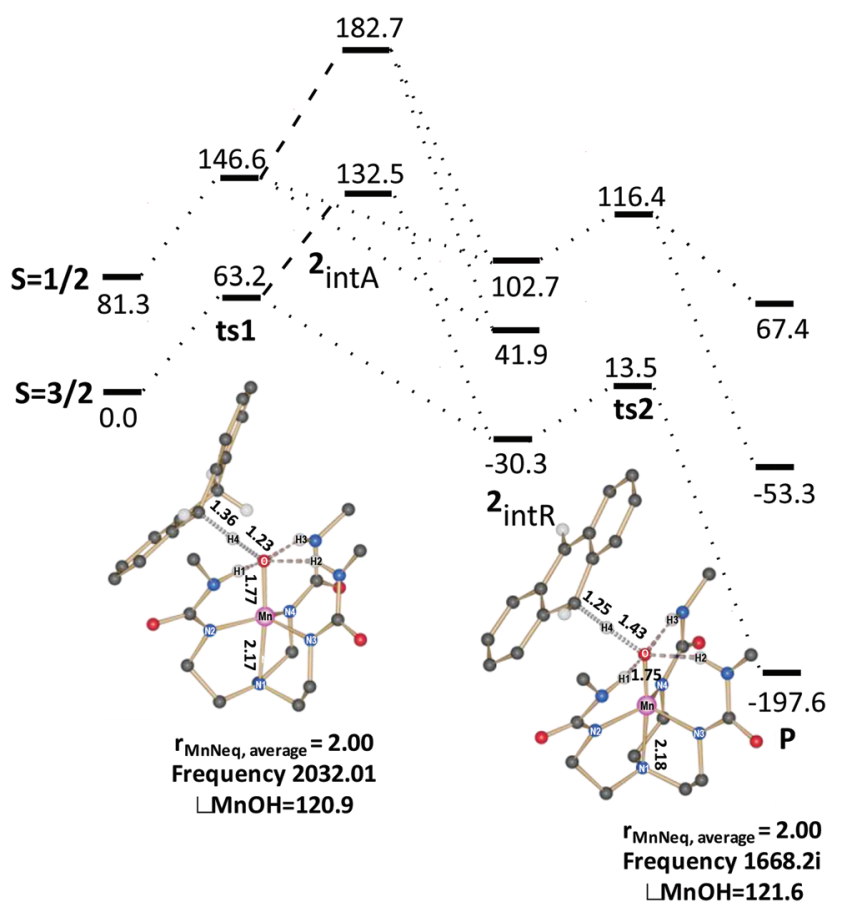

Fig. 2 Computed reaction profile of $\mathrm{C}-\mathrm{H}$ activation reaction involving DHA and species 2.

(Fig. 1 and 2). The $\mathrm{Mn}^{\mathrm{III} / \mathrm{IV}}=\mathrm{O}$ bond in $\mathbf{1}$ and 2 is stabilized predominately by the presence of the intramolecular H-bonds between the terminal oxo ligand with H-bond donors of the ureate nitrogen atoms. The $\mathrm{Mn}-\mathrm{O}$ bond length in species 2
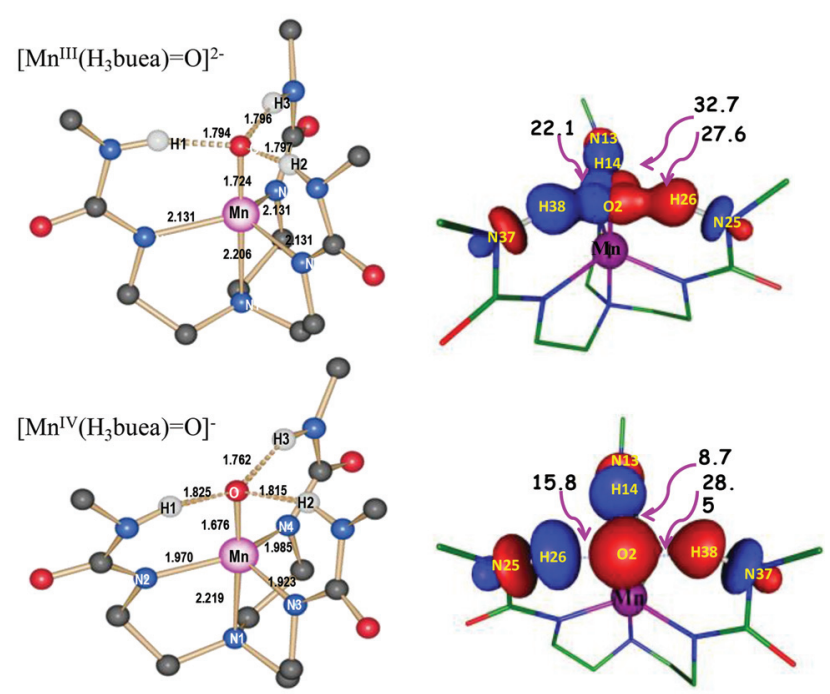

Fig. 3 (a) Optimized geometries of species $\mathbf{1}$ and $\mathbf{2}$ along with geometrical parameters and (b) weak $\mathrm{H}$-bond stabilization interaction between $\mathrm{O}(\mathrm{LP}) \rightarrow$ $\mathrm{BD}^{*}(\mathrm{NH})$ bonds.

$(1.68 \AA)$ is found to be shorter than that of species $1(1.73 \AA)$ (shown in Fig. 3 and Table S1 of ESI $\ddagger$ ), this shorter and stronger $\mathrm{Mn}=\mathrm{O}$ bond observed in 2 is also reflected in the computed bond order (Wiberg bond index of 1.16 vs. 1.32 for 1 and 2 respectively). The computed $\mathrm{Mn}-\mathrm{O}$ bond lengths and other structural parameters are in agreement with the reported X-ray ${ }^{47-52}$ and previous theoretical studies. ${ }^{53-55}$ In addition to this, the Mulliken spin density on the oxo-oxygen in species 2 $\left(\rho_{\mathrm{Mn}}=2.6, \rho_{\mathrm{O}}=0.26\right.$, Fig. 4 and Table S2 of ESI $\neq$ ) is substantially delocalized more than that of the oxo-oxygen in species 1 $\left(\rho_{\mathrm{Mn}}=3.7, \rho_{\mathrm{O}}=0.13\right.$, Fig. 4 and Table S2 of ESI $\ddagger$ ). This implies that species 2 is having larger $\mathrm{Mn}-\mathrm{O}$ covalent bond character and that leads to a shorter $\mathrm{Mn}-\mathrm{O}$ bond. Further we would like to note here that the spin density on the oxygen atoms for both the species is significantly less compared to the corresponding iron-oxo species ${ }^{5}$ and thus can very well be denoted as metal-oxo complexes rather than oxy-radical type species. Moreover, species 1 is found to have shorter $\mathrm{Mn}-\mathrm{N}_{\mathrm{eq}}$ bonds (average $\mathrm{Mn}-\mathrm{N}_{\mathrm{eq}}$ bond length $=2.13 \AA$ ) and longer $\mathrm{Mn}-\mathrm{N}_{\mathrm{ax}}$ bonds $(2.21 \AA)$. In 2 although the same trend is visible, the $\mathrm{Mn}-\mathrm{N}_{\mathrm{ax}}$ bonds are much longer and $\mathrm{Mn}-\mathrm{N}_{\mathrm{eq}}$ bond are much shorter than that of $\mathbf{1}$. A shorter and stronger $\mathrm{Mn}-\mathrm{O}$ bond attributes to longer $\mathrm{Mn}-\mathrm{N}_{\mathrm{ax}}$ bonds in the high-valent $\mathrm{Mn}^{\mathrm{IV}}=\mathrm{O}$ species. ${ }^{56}$ The larger basicity of species 1 compared to species 2 is also reflected in the computed NPA charges $(-0.82 v s$. -0.63 for 1 and 2 respectively). Due to this variation in the basicity, the strength of three weak $\mathrm{N}-\mathrm{H} \cdots \mathrm{O}(\mathrm{Mn})$ hydrogen bonding interactions also varies significantly between $\mathbf{1}$ and $\mathbf{2}$. The three weak $\mathrm{N}-\mathrm{H} \cdots \mathrm{O}(\mathrm{Mn})$ hydrogen bond lengths are equal $(1.79 \AA)$ in 1 while they differ drastically in 2 (see Fig. 3 ). On comparing with species 1 , the weak $\mathrm{N}-\mathrm{H} \cdots \mathrm{O}(\mathrm{Mn})$ bonds are elongated by $0.025-0.035 \AA$ in 2 while the $\mathrm{N}-\mathrm{H}$ distances are proportionately shortened. The longer and weaker $\mathrm{N}-\mathrm{H} \cdots \mathrm{O}(\mathrm{Mn})$ distances in 2 are also reflected in the 

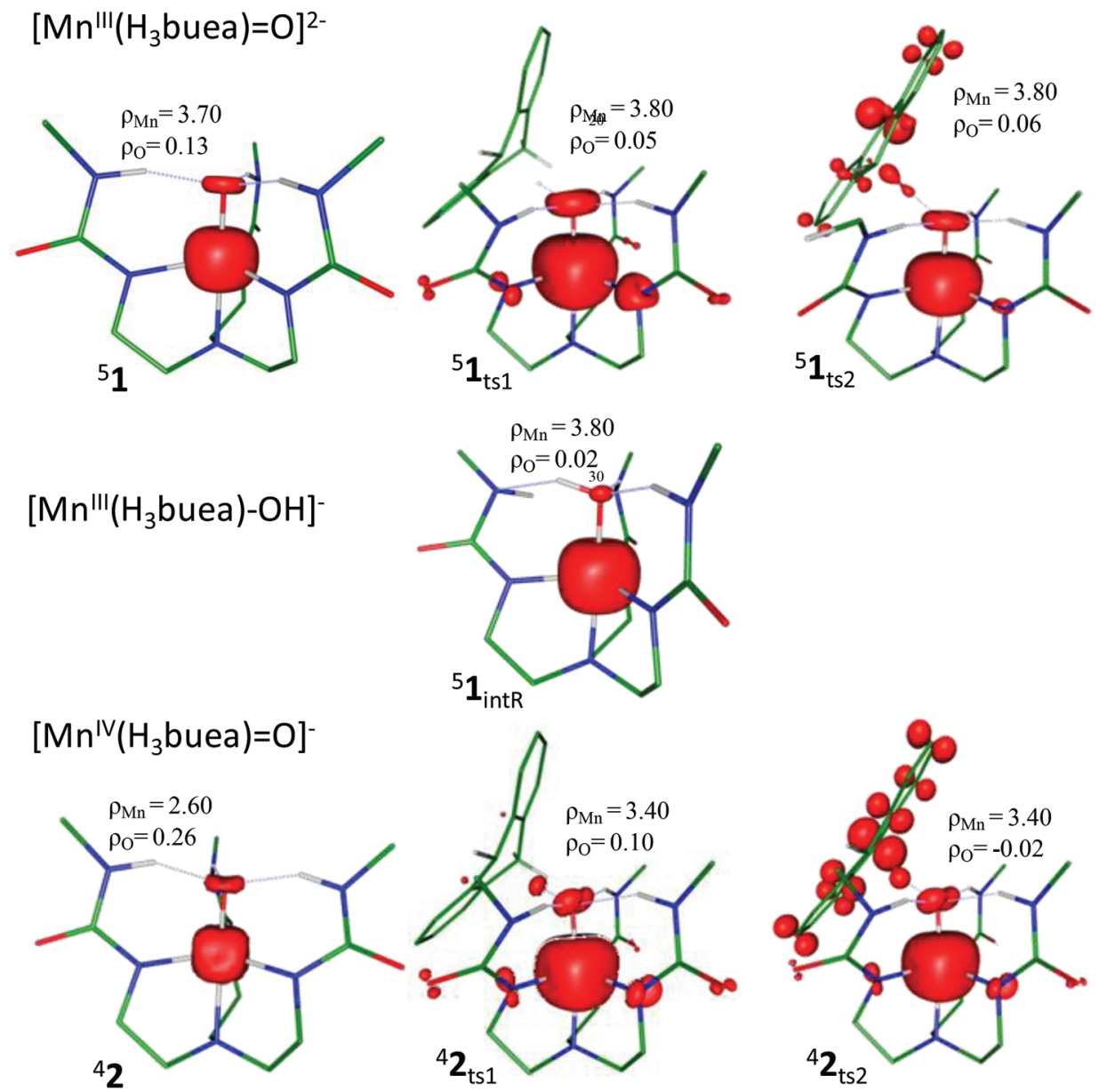

Fig. 4 Computed spin density plots for ts 1 , ts 2 and ${ }^{5} \mathbf{1}_{\text {intR }}$ of species $\mathbf{1}$ and $\mathbf{2}$

$\mathrm{O}_{\mathrm{LP}} \rightarrow \mathrm{BD}_{\mathrm{N}-\mathrm{H}}^{*}$ donor-acceptor interactions in the $\mathrm{NBO}$ analysis. For 1 the stabilization energies are found to be in the range of 32.7-22.1 $\mathrm{kJ} \mathrm{mol}^{-1}$ while for 2 they are in the range of 28.5-8.7 $\mathrm{kJ} \mathrm{mol}^{-1}$. These electronic and structural differences between 1 and 2 hold the key to the difference in the reactivity between these two species. ${ }^{57}$

Based on the computed reaction profile diagram (Fig. 1 and 2), it is clear that the $\mathrm{C}-\mathrm{H}$ activation of DHA by these two oxidants occurs on the high spin surface. The high spin $S=2$ surface in $\mathbf{1}$ is well separated from other spin states which suggests that the excited spin states are unlikely to participate in the reaction mechanism. The barrier for the proton transfer $\left({ }^{5} \boldsymbol{1}_{\mathrm{ts} 1}\right)$ from DHA is estimated to be $54.2 \mathrm{~kJ} \mathrm{~mol}^{-1}$ and the proton transfer leads to the formation of an anionic intermediate $\left({ }^{5} \mathbf{1}_{\text {intA }}\right)$. This step is estimated to be endothermic $(+52.4 \mathrm{~kJ}$ $\mathrm{mol}^{-1}$ ) in nature. In the next step this intermediate undergoes a rapid electron transfer from the anionic DHA to the metal complex and this leads to a radical intermediate $\left({ }^{5} \mathbf{1}_{\text {intR }}\right)$. This radical intermediate is stabilized by $41.3 \mathrm{~kJ} \mathrm{~mol}^{-1}$ compared to the ${ }^{5} \mathbf{1}_{\text {intA }}$ intermediate suggesting that the electron transfer is feasible and the reaction proceeds further from the ${ }^{5} \mathbf{1}_{\text {intR }}$ species. For species 2 the initial hydrogen abstraction $\left({ }^{4} \boldsymbol{2}_{\mathrm{ts} 1}\right)$ from DHA requires a barrier height of $63.2 \mathrm{~kJ} \mathrm{~mol}^{-1}$ which is slightly higher than that computed for species $\mathbf{1}$. In contrast to the mechanistic steps described for $\mathbf{1}$, in $\mathbf{2}$ the formation of the radical intermediate ${ }^{4} \boldsymbol{2}_{\text {intR }}$ is thermodynamically more favored compared to the anionic intermediate ${ }^{4} \boldsymbol{2}_{\text {inta }}$ (energy margin of $162.8 \mathrm{~kJ} \mathrm{~mol}^{-1}$ ). Also the nature of the transition state advocates the direction of the course of reaction that the species go forth. Comparing just the $\mathrm{Mn}-\mathrm{O}$ bond distance, it is clear that species ${ }^{5} \mathbf{1}_{\mathrm{ts} 1}$ is reactant like while the ${ }^{4} \boldsymbol{2}_{\mathrm{ts} 1}$ is product like (see Table S1 of ESI $\ddagger$ ). In case of ${ }^{4} \boldsymbol{2}_{\mathrm{ts} 1}$, significant spin densities are detected at the DHA moiety (group spin densities on the DHA $\rho_{\text {DHA }}=-0.25$ ) suggesting a development of a partial radical character at the transition state (see Fig. 4). The computed energetics and the electronic structure is consistent with earlier theoretical reports on a $\mathrm{Mn}^{\mathrm{IV}}=\mathrm{O}$ complexes. ${ }^{58} \mathrm{~A}$ similar radicaloid character for the transition state has also been reported for the non-heme $\mathrm{Fe}^{\mathrm{IV}}=$ O species. ${ }^{59}$ In ${ }^{5} \mathbf{1}_{\mathrm{ts} 1}$ the DHA moiety is found to have negligible spin densities $\left(\rho_{\text {DHA }}=0.01\right)$ but a large accumulated negative charge and this suggests a preference for an anionic type intermediate in this case. For species $\mathbf{1}$, although the ${ }^{5} \mathbf{1}_{\text {intA }}$ and ${ }^{5} \mathbf{1}_{\text {intA }}$ species are not separated by an energy barrier, these two species are related by one electron being in DHA or in the $\mathrm{Mn}^{\mathrm{III}}=\mathrm{O}$ complex. The nature of the transition state clearly reveals that it is converging to an 
anionic intermediate and does not possess any radical character. Although the anionic and radical intermediate in the potential energy surface is shown to have no barrier, the electron transfer from the $\mathrm{MHA}^{-}$to $\mathrm{MH}^{*}$ might have some barrier associated with the deformation of MHA molecule, besides the potential energy surface for such reactions are likely to be multidimensional in nature and thus warrant a valence-bond theory based approach ${ }^{60}$ to further probe the nature of the transition state. As far as other spin states of the metal-oxo complexes are concerned, those states are very high in energy compared to the ground state. Although their structure and bonding are not described here, a similar scenario to the ground state is also witnessed for other excited spin states for both 1 and 2 (see ESI Table S1 and Fig. S1 for the optimized structures of the transition states). Put together, all these data clearly indicates that $\mathbf{1}$ and $\mathbf{2}$ proceeds via different routes with the former favoring an anionic intermediate while for the latler the reaction is routed through a radical intermediate.

\section{Electronic structure origin of difference in the reactivity}

The energy decomposition analysis (EDA) were performed for 1 and 2 by treating $\mathrm{H}_{3}$ buea, $\mathrm{Mn}$ and $\mathrm{O}$ as separate fragments $\left(\mathrm{H}_{3}\right.$ buea $+\mathrm{Mn}+\mathrm{O}$, see Table 1$)$. The EDA results for $\mathbf{1}$ and 2 show that $\Delta E_{\text {int }}$ for $\mathrm{Mn}^{\mathrm{IV}}=\mathrm{O}$ is 1.6 times larger than that of the $\mathrm{Mn}^{\mathrm{III}}=\mathrm{O}$ suggesting that species 2 is very stable compared to species $\mathbf{1}$ and accounts for the fact that $\mathbf{1}$ is more reactive than 2. A significant contribution to the interaction energy for 2 arise from orbital stabilization and this indicates a stronger $\mathrm{Mn}-\mathrm{L}$ bond, particularly the Mn-oxo bond for 2 compared to 1 .

The trigonal bipyramidal structure observed in $\mathbf{1}$ and $\mathbf{2}$ and its related frontier orbitals are entirely different from that of an octahedral complexes of high-valent manganese or iron-oxo species. ${ }^{61}$ Fig. 5 and 6 show the FMO of the ${ }^{5} \mathbf{1}$ and ${ }^{4} \mathbf{2}$ and their respective first transition states. The occupation of four electrons in ${ }^{5} 1$ is found to be in $\pi_{x z^{1}}^{*} \pi_{y z^{1}}^{*} \delta_{x y^{1}} \delta_{x^{2} z^{2}}^{1} \sigma_{z^{2}}^{0}$ in which the two $\pi^{*}$ orbitals $\left(\pi_{x z}^{*}\right.$ and $\left.\pi_{y z}^{*}\right)$ are degenerate, similarly the two $\delta$ orbitals $\left(\delta_{x y}\right.$ and $\left.\delta_{x^{2}-y^{2}}\right)$ are also degenerate and lie $0.35 \mathrm{eV}$ higher in energy with respect to the $\pi^{*}$ orbitals. The empty $\sigma_{z^{2}}$ orbital is found to lie much higher at $4.19 \mathrm{eV}$. In the transition state ${ }^{5} \boldsymbol{1}_{\mathrm{ts} 1}$, the degeneracy of the $\pi^{*}$ and $\delta$ orbitals are slightly perturbed and the $\delta$-type orbitals are further destabilized. In the case of ${ }^{5} \boldsymbol{2}$, the three unpaired electrons are found to be in $\pi_{x z^{1}}^{*} \pi_{y z^{1}}^{*} \delta_{x y^{1}} \delta_{x^{2} z^{2}}^{0} \sigma_{z^{2}}^{0}$ orbitals. Unlike in $\mathbf{1}$, here the degeneracy of the two $\pi^{*}$ orbitals $\left(\pi_{x z}^{*}\right.$ and $\left.\pi_{y z}^{*}\right)$ are lifted and the $\sigma_{z^{2}}$ orbital is significantly destabilized. In the first transition state ${ }^{4} \boldsymbol{2}_{\mathrm{ts} 1}$, one of the $\mathrm{C}-\mathrm{H}$ bond electron is found to be transferred to $\delta_{x^{2}-y^{2}}$ orbitals (vide infra) and this reduces the energy gap between the $\pi_{x z}^{*}$ and $\pi_{y z}^{*}$ orbitals (see Scheme 2). We would like to note here that earlier report on an octahedral $\mathrm{Mn}^{\mathrm{IV}}=\mathrm{O}$ species suggest such a transfer to $\pi_{x z}^{*}$ orbital while here our calculations indicate the electron being transferred to $\delta$ type $\delta_{x^{2}-y^{2}}$ orbital. $^{59}$ This orbital has significant density on the oxygen and also the orbital is polarized to accept the electron (see Fig. 6). Such electron transfer does not occur in ${ }^{5} \mathbf{1}_{\text {ts1 }}$ for two reasons: (i) electron transfer to $\sigma_{z^{2}}^{*}$

Table 1 Summary of EDA performed for species $\mathbf{1}$ and $\mathbf{2}$. The $\Delta E$ are given in $\mathrm{kJ} \mathrm{mol}^{-1}$

\begin{tabular}{llc}
\hline Species & & $\left\{\mathrm{H}_{3} \mathrm{buea}+\mathrm{Mn}+\mathrm{O}\right\}$ \\
\hline 1 & $\Delta E_{\text {int }}$ & -8609.7 \\
& $\Delta E_{\text {steric }}$ & -6305.2 \\
2 & $\Delta E_{\text {orb }}$ & -2304.5 \\
& $\Delta E_{\text {int }}$ & -14096.2 \\
& $\Delta E_{\text {steric }}$ & -9339.0 \\
& $\Delta E_{\text {orb }}$ & -4757.2
\end{tabular}

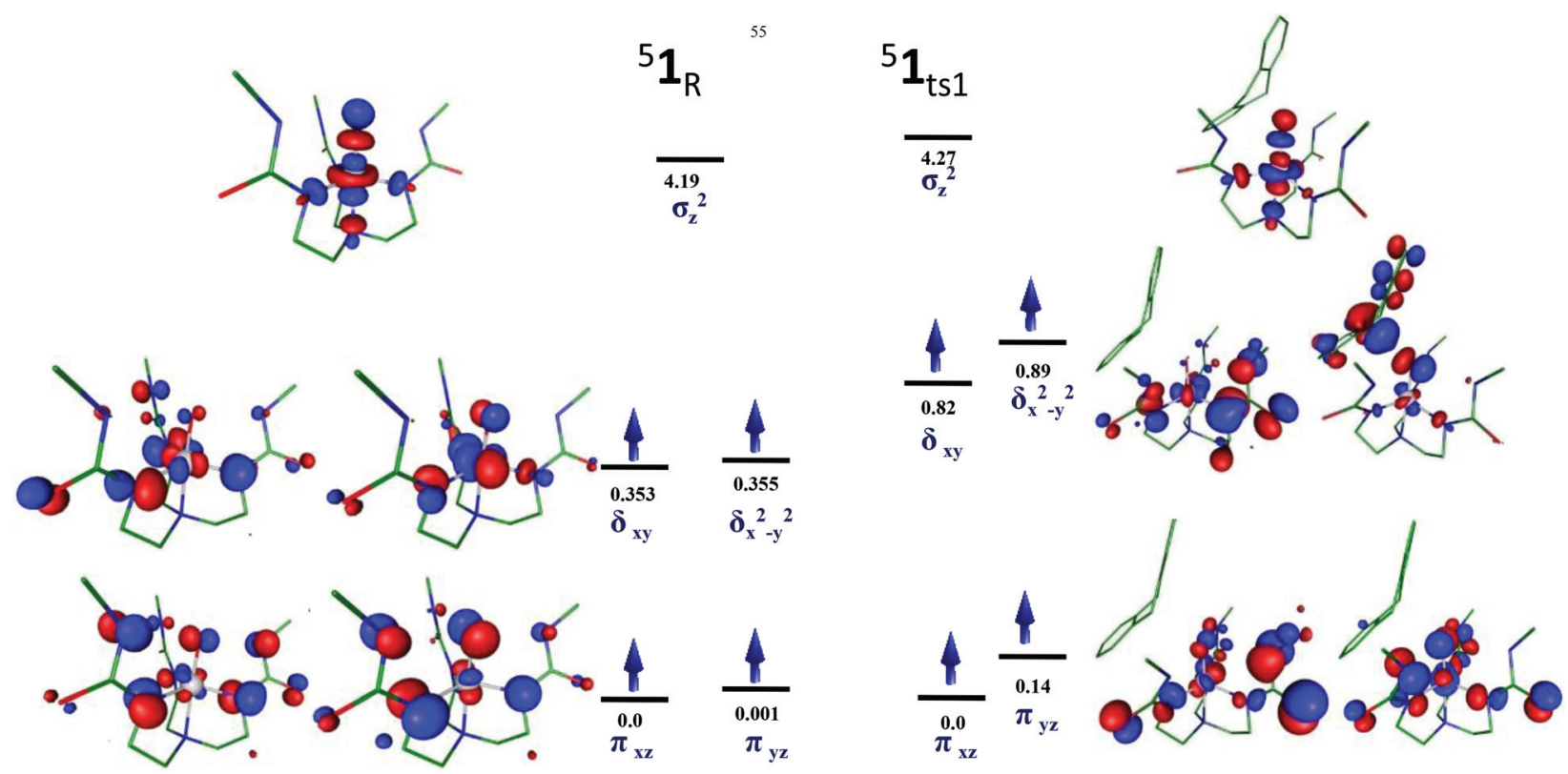

Fig. 5 Schematic MO diagrams of species $\mathbf{1}$ and its corresponding first transition state ${ }^{5} \mathbf{1}_{\mathrm{ts} 1}$. The energy differences given here are in eV. 


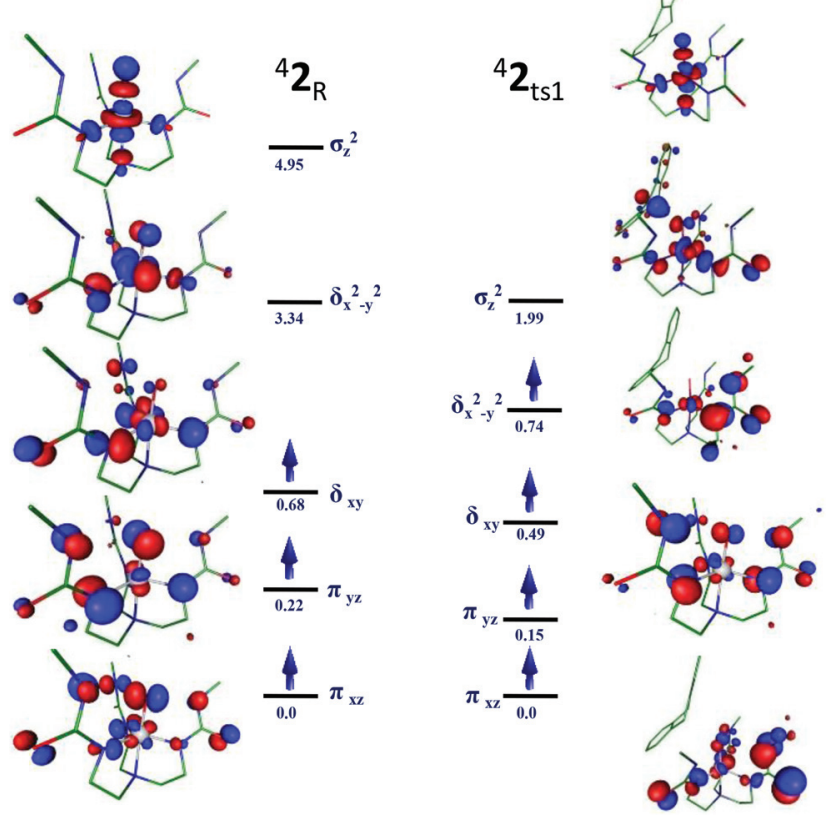

Fig. 6 Schematic MO diagrams of species $\mathbf{2}$ and its corresponding first transition state ${ }^{4} \mathbf{2}_{\mathrm{ts}}$. The energy differences given here are in $\mathrm{eV}$.

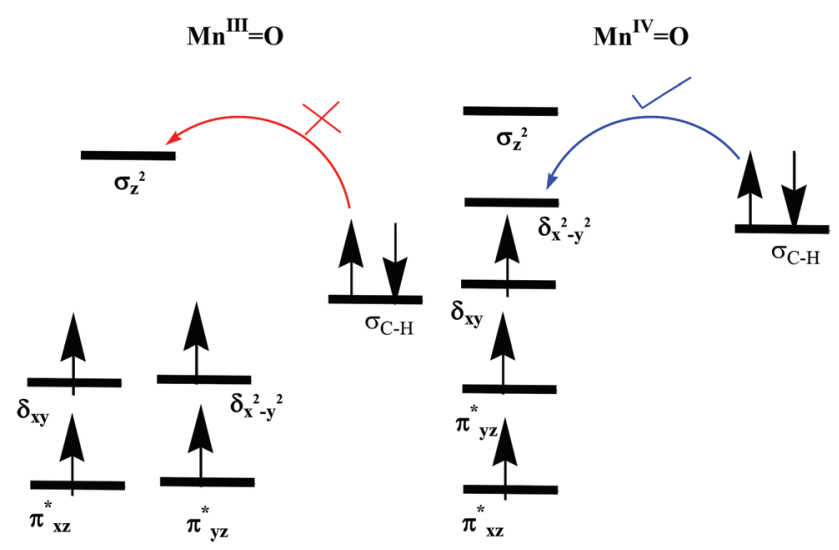

Scheme 2 The feasible electron shifts between the $\sigma_{\mathrm{C}-\mathrm{H}}$ bond and $\mathrm{Mn}-\mathrm{O}$ $\mathrm{d}$-based orbitals for $\mathrm{Mn}^{\mathrm{II}}=\mathrm{O}$ and $\mathrm{Mn}^{\mathrm{IV}}=\mathrm{O}$ species.

demands a very high energy as this orbital is significantly destabilized, (ii) the other option of transferring the downward spin electron ( $\beta$-electron) of the $\sigma_{\mathrm{C}-\mathrm{H}}$ bond to the singly occupied orbitals will lift the degeneracy and this again will demand a significant energy (see Scheme 2). The above two factors in fact favour electron transfer in 2 where the $\delta_{x^{2}-y^{2}}$ orbital is not too high lying (see Scheme 2) and other singly occupied orbitals are non-degenerate and thus the $\mathrm{Mn}^{\mathrm{IV}}=\mathrm{O}$ readily accepts an electron from the DHA leading to a transition state with a $\mathrm{Mn}^{\mathrm{III}}-\mathrm{OH}$ like character.

\section{Thermodynamic rational for the difference in the reactivity}

To understand the origin of the difference in the mechanism and to probe various possible pathways by which the hydrogen
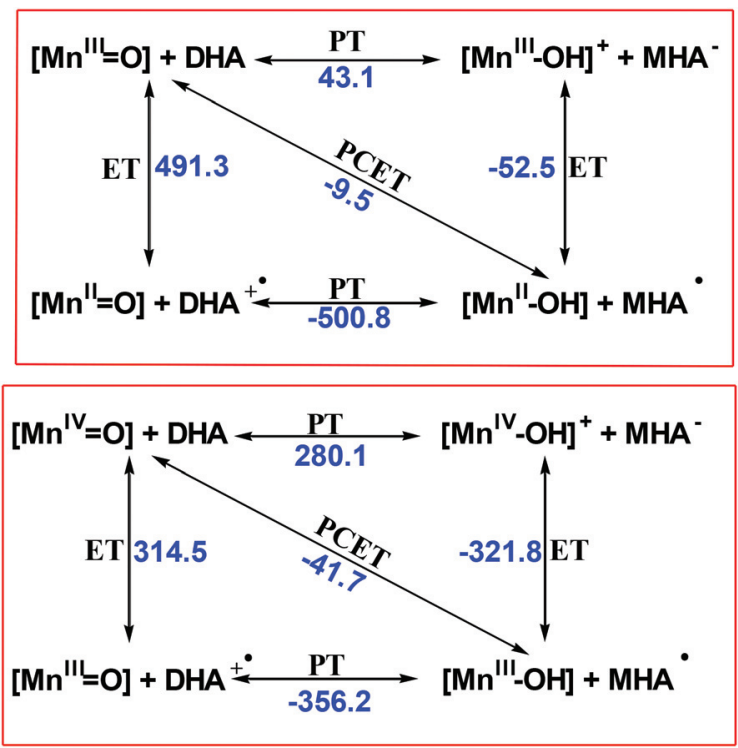

Fig. 7 Relative thermodynamic free energies between $M n^{111 / 1 \mathrm{IV}}=\mathrm{O}$ and its hydroxo complexes.

atom transfer can takes place (PT-ET, ET-PT and PCET), a thermodynamic formation energy cycle for the $\mathrm{Mn}^{\mathrm{III}}=\mathrm{O}$ and $\mathrm{Mn}^{\mathrm{IV}}=\mathrm{O}$ has been constructed ${ }^{62}$ and is shown in Fig. 7. A quick look at the thermodynamic energies suggests a favourable PCET for both the species, however if the kinetic results discussed above are assimilated, one can easily differentiate the subtle mechanistic change between the two species. The first transition state for the $\mathrm{Mn}^{\mathrm{III}}=\mathrm{O}$ species is clearly a PT transition state as discussed above and thermodynamics suggest that this step is endothermic by $43.1 \mathrm{~kJ} \mathrm{~mol}^{-1}$ and the subsequent ET step more than compensate the energy loss, leading to the final $\left[\mathrm{Mn}^{\mathrm{II}}-\mathrm{OH}\right]$ product. Given the barrier height of $52.5 \mathrm{~kJ} \mathrm{~mol}^{-1}$ for the first transition state, a metastable $\left[\mathrm{Mn}^{\mathrm{III}}-\mathrm{OH}\right]^{+}$species is certainly feasible (note the characterized transition state has a strong $\mathrm{Mn}^{\mathrm{III}}-\mathrm{OH}$ character, see below) and thus one can suggest a PT-ET mechanism is operational for this species. On the other hand, the ET-PT mechanism is unlikely as the ET step is exceedingly endothermic compared to the transition state barrier, thus the transition state is unlikely to converge to a $\left[\mathrm{Mn}^{\mathrm{II}}=\mathrm{O}\right]$ meta-stable species. The spin density plots of $\mathrm{Mn}^{\mathrm{III}}=\mathrm{O},{ }^{5} \mathbf{1}_{\mathrm{ts} 1}$ and high-spin state of $\left[\mathrm{Mn}^{\mathrm{III}}-\mathrm{OH}\right]$ are shown in Fig. 4 . As one can see the transition state clearly resembles $\left[\mathrm{Mn}^{\mathrm{III}}-\mathrm{OH}\right]$ type species (3.776 vs. 3.783) and this affirmatively suggests that the reaction proceed through a PT-ET mechanism here and not a through a PCET or ET-PT mechanism.

Unlike 1, for species 2 both the initial PT (for PT-ET mechanism) and the alternative initial ET (for ET-PT mechanism, see Fig. 7) steps are exceedingly endothermic and are much higher than the barrier height computed for ${ }^{4} 2_{\mathrm{ts} 1}(63.2 \mathrm{~kJ}$ $\mathrm{mol}^{-1}$ ). The spin density plots for the $\mathrm{Mn}^{\mathrm{IV}}=\mathrm{O},{ }^{4} \mathbf{2}_{\mathrm{ts} 1}$ and $\mathrm{Mn}^{\mathrm{III}}-\mathrm{OH}$ are shown in Fig. 4 clearly suggest that the transition state here also resembles the $\left[\mathrm{Mn}^{\mathrm{III}}-\mathrm{OH}\right]$ type species (spin density values $2.60 v s$. 3.40 in 2 and ${ }^{4} 2_{\text {ts } 1}$ respectively) and not 
$\left[\mathrm{Mn}^{\mathrm{IV}}-\mathrm{OH}\right]^{+}$and this clearly directs the discussion towards a concerted PCET mechanism for species 2 . This step is an energetically favourable process $\left(-41.7 \mathrm{~kJ} \mathrm{~mol}^{-1}\right)$. The reason for the difference between $\mathbf{1}$ and $\mathbf{2}$ is related to the stability of the electronically preferred $\left[\mathrm{Mn}^{\mathrm{III}}-\mathrm{OH}\right]$ type species, independent of the starting oxidation state of the oxo species. As the $\mathrm{Mn}-\mathrm{O}$ bonds are stronger and less basic in $\mathrm{Mn}^{\mathrm{IV}}=\mathrm{O}$ compared to $\mathrm{Mn}^{\mathrm{III}}=\mathrm{O}$, a protonated meta-stable intermediate for the $\mathrm{Mn}^{\mathrm{IV}}=\mathrm{O}$ is extremely unstable and this leads to a switch in the mechanism. Thus the thermodynamic cycle constructed essentially verifies the mechanistic insights discussed earlier and provide confidence to the established mechanism for species 1 and 2.

\section{Second HAT reaction}

The second hydrogen abstraction takes place $\left({ }^{5} \mathbf{t}_{\mathrm{ts} 2}\right)$ with the barrier of $21.3 \mathrm{~kJ} \mathrm{~mol}^{-1}$ and leads to the formation of anthracene in 1. For 2, the barrier height for second hydrogen abstraction $\left({ }^{4} 2_{\mathrm{ts} 2}\right)$ is computed to be $43.8 \mathrm{~kJ} \mathrm{~mol}^{-1}$. In accord to the first step the second hydrogen atom transfer reaction is also found to proceed via the similar mechanism, i.e. species $\mathbf{1}$ is found to follow a PT-ET mechanism while 2 is found to follow a PCET path. This is again easily visible from the spin density plots computed for the ${ }^{5} \mathbf{1}_{\mathrm{ts} 2}$ and ${ }^{4} \boldsymbol{2}_{\text {ts2 }}$ species (see Fig. 4) where again both the species resemble a $\left[\mathrm{Mn}^{\mathrm{III}}-\mathrm{OH}\right]$ complex as discussed for the first hydrogen atom transfer reaction.

\section{Correlation to experiments}

Comparing both the transition states ts1 and ts2 barrier heights for both the species, it is clear that for both the species the first transition state is the rate-limiting. The computed barrier height of 54.2 (for 1) and $63.2 \mathrm{~kJ} \mathrm{~mol}^{-1}$ for the rate-determining step correlates well with the experimental kinetic data $\left(75.3\right.$ and $79.5 \mathrm{~kJ} \mathrm{~mol}^{-1}$ for species $\mathbf{1}$ and 2 respectively), although the absolute values are slightly underestimated. ${ }^{18}$ Besides the computed imaginary frequencies corresponding to the transition states ${ }^{5} \mathbf{1}_{\mathrm{ts} 1}$ and ${ }^{5} \mathbf{1}_{\mathrm{ts} 2}$ are 1280.9i and $1191.7 \mathrm{i}$ respectively while for ${ }^{4} 2_{\mathrm{ts} 1}$ and ${ }^{4} 2_{\mathrm{ts} 2}$ are $2032 \mathrm{i}$ and 1668.2i respectively. Larger imaginary frequencies are obtained for species 2 compared to species $\mathbf{1}$ and this suggest a large tunneling contribution for 2 and a narrow and sharper reaction barrier than that of $\mathbf{1}$. This is clearly envisaged from the larger kinetic isotopic effect (KIE) values (6.8) obtained for species 2 .

\section{Conclusions}

DFT calculation have been used to investigate the kinetic aspects of the $\mathrm{C}-\mathrm{H}$ bond activation reactions of monomeric $\mathrm{Mn}^{\text {III/IV }}=$ oxo units with tetradentate tripodal ligands. The initial $\mathrm{H}$-abstraction on the high spin surface is found to be the rate determining step for both the species $\mathbf{1}$ and 2. From a detailed electronic and structural analysis of the transition states along with the computation of reaction energies of

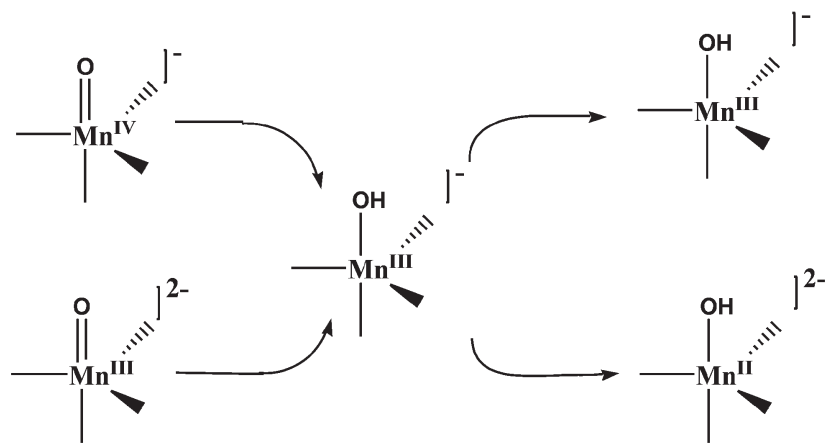

Scheme 3 A schematic DFT computed mechanism for HAT reaction by $\mathrm{Mn}^{\mathrm{II}}=\mathrm{O}$ and $\mathrm{Mn}^{\mathrm{IV}}=\mathrm{O}$ complexes.

various species in the hydrogen atom transfer reaction, our calculations unequivocally suggest that the highly reactive $\mathbf{1}$ prefers to undergo a step-wise proton transfer followed by electron transfer (PT-ET) mechanism while relatively less reactive 2 prefers a concerted proton-coupled electron transfer (PCET) path (see Scheme 3). This drastic difference in reactivity between 1 and 2 is mainly attributed to the strength of the $\mathrm{Mn}=\mathrm{O}$ bond, its basicity and the nature of electron delocalization during the $\mathrm{C}-\mathrm{H}$ bond activation. Interestingly the computed transition state for the hydrogen atom transfer reactions for the $\mathrm{Mn}^{\mathrm{III}}=\mathrm{O}$ and $\mathrm{Mn}^{\mathrm{IV}}=\mathrm{O}$ species reveal the course of the reaction where structurally and electronically resembling $\left[\mathrm{Mn}^{\mathrm{III}}-\mathrm{OH}\right]$ like transition state has been detected for both the species. This essentially en route to a PT-ET type mechanism for $\mathbf{1}$ and a PCET mechanism for species $\mathbf{2}$. All our computed results are in excellent agreement to the experimental reports.

Although the presented results are likely to be general for $\mathrm{Mn}^{\mathrm{III} / \mathrm{IV}}=\mathrm{O}$ species with different set of ligand architecture, factors which are expected to directly affect the $\mathrm{Mn}-\mathrm{O}$ bond covalency (such as $\mathrm{H}$-bonding interaction etc.) can lead to some difference in the predicted reactivity pattern.

To this end, here for the first time using DFT methods we have demonstrated that a subtle mechanistic difference in hydrogen atom transfer reactions for such large metal-oxo complexes can be apprehended if an apt bunch of computational tools are employed (PES modelling, reaction energy computation, $\mathrm{MO} / \mathrm{NBO}$ analysis). This procedure will be expanded to other examples in future.

\section{Acknowledgements}

GR would like to acknowledge financial support from the Government of India through the Department of Science and Technology (SR/S1/IC-41/2010; SR/NM/NS-1119/2011) and Indian Institute of Technology, Bombay to access the high performance computing facility. MJ would like to thank IITB for postdoctoral fellowship, AA to CSIR New Delhi for JRF fellowship and BP would like to thank UGC New Delhi for JRF fellowship. 


\section{Notes and references}

1 (a) O. Hayaishi, Molecular Mechanism of Oxygen Activation, Academic Press, New York, 1974; (b) M.-H. Baik, M. Newcomb, R. A. Friesner and S. J. Lippard, Chem. Rev., 2003, 103, 2385-2419.

2 A. E. Shilov and G. B. Shul'pin, Chem. Rev., 1997, 97, 28792932.

3 A. Gunay and K. H. Theopold, Chem. Rev., 2010, 110, 10601081.

4 W. Nam, Acc. Chem. Res., 2007, 40, 522-531.

5 B. Meunier, S. P. de Visser and S. Shaik, Chem. Rev., 2004, 104, 3947-3980.

6 (a) M. M. Abu-Omar, A. Loaiza and N. Hontzeas, Chem. Rev., 2005, 105, 2227-2252; (b) D. Balcells, E. Clot and O. Eisenstein, Chem. Rev., 2010, 110, 749-823.

7 M. Costas, M. P. Mehn, M. P. Jensen and L. Que Jr., Chem. Rev., 2004, 104, 939-986.

8 L. Que Jr. and R. Y. N. Ho, Chem. Rev., 1996, 96, 26072624.

9 A. S. Borovik, Chem. Soc. Rev., 2011, 40, 1870-1874.

10 (a) Cytochrome P450: Structure, Mechanism and Biochemistry, ed. P. R. Ortiz de Montellano, Plenum, New York, 1995; (b) J. M. Bollinger Jr. and C. Krebs, J. Inorg. Biochem., 2006, 100, 586-605.

11 L. M. Hoffart, E. W. Barr, R. B. Guyer, J. M. Bollinger Jr. and C. Krebs, Proc. Natl. Acad. Sci. U. S. A., 2006, 103, 14738-14743.

12 D. P. Galonic, E. W. Barr, C. T. Walsh, J. M. Bollinger Jr. and C. Krebs, Nat. Chem. Biol., 2007, 3, 113-116.

13 C. Krebs, D. G. Fujimori, C. T. Walsh and J. M. Bollinger Jr., Acc. Chem. Res., 2007, 40, 484-492.

14 C. V. Sastri, J. Lee, K. Oh, Y. J. Lee, J. Lee, T. A. Jackson, K. Ray, H. Hirao, W. Shin, J. A. Halfen, J. Kim, L. Que Jr., S. Shaik and W. Nam, Proc. Natl. Acad. Sci. U. S. A., 2007, 104, 19181-19186.

15 D. E. Lansky and D. P. Goldberg, Inorg. Chem., 2006, 45, 5119-5125.

16 M. T. Green, J. H. Dawson and H. B. Gray, Science, 2004, 304, 1653-1656.

17 K. A. Prokop, S. P. de Visser and D. P. Goldberg, Angew. Chem., Int. Ed., 2010, 49, 5091-5095.

18 T. H. Parsell, M.-Y. Yang and A. S. Borovik, J. Am. Chem. Soc., 2009, 131, 2762-2763.

19 J. P. Roth and J. M. Mayer, Inorg. Chem., 1999, 38, 27602761.

20 Y. Wang, H. Hirao, H. Chen, H. Onaka, S. Nagano and S. Shaik, J. Am. Chem. Soc., 2008, 130, 7170-7171.

21 Y. Wang, H. Chen, M. Makino, Y. Shiro, S. Nagano, S. Asamizu, H. Onaka and S. Shaik, J. Am. Chem. Soc., 2009, 131, 6748-6762.

22 J. J. Warren, T.A. Tronic and J. M. Mayer, Chem. Rev., 2010, 110, 6961-7001.

23 O. Tishchenko, D. G. Truhlar, A. Ceulemans and M. T. Nguyen, J. Am. Chem. Soc., 2008, 130, 70007010 .
24 S. Hammes-Schiffer and A. V. Soudackov, J. Phys. Chem. B, 2008, 112, 14108-14123.

25 M. J. Frisch, et al., GAUSSIAN 09 (Revision 02), Gaussian, Inc., Wallingford, CT, 2009.

26 C. Lee, W. Yang and R. G. Parr, Phys. Rev. B, 1988, 37, 785789.

27 A. D. Becke, J. Chem. Phys., 1993, 98, 5648-5652.

28 H. Hirao, D. Kumar, L. Que and S. Shaik, J. Am. Chem. Soc., 2006, 128, 8590-8606.

29 C. M. Bathelt, J. Zurek, A. J. Mulholland and J. N. Harvey, J. Am. Chem. Soc., 2005, 127, 12900-12908.

30 P. E. M. Siegbahn and T. Borowski, Acc. Chem. Res., 2006, 39, 729-738.

31 T. H. J. Dunning and P. J. Hay, in Modern Theoretical Chemistry, ed. H. F. Schaefer III, Plenum, New York, 1976, vol. 3, p. 1.

32 P. J. Hay and W. R. Wadt, J. Chem. Phys., 1985, 82, 270-283.

33 W. R. Wadt and P. J. Hay, J. Chem. Phys., 1985, 82, 284-298.

34 P. J. Hay and W. R. Wadt, J. Chem. Phys., 1985, 82, 299310.

35 R. Ditchfield, W. J. Hehre and J. A. Pople, J. Chem. Phys., 1971, 54, 724-728.

36 A. Schaefer, H. Horn and R. Ahlrichs, J. Chem. Phys., 1992, 97, 2571-2577.

37 C. Schaefer, C. Huber and R. Ahlrichs, Chem. Phys., 1994, 100, 5829-5835.

38 P. Fluckiger, H. P. Luthi, S. Portmann and J. Weber, Molekel 4.3, Swiss Center for Scientific Computing, Manno, Switzerland, 2000.

39 S. Portmann and H. P. Luthi, Chimia, 2000, 54, 766-770.

40 L. Noodleman and W. G. Han, JBIC, J. Biol. Inorg. Chem., 2006, 11, 674-694.

41 K. Morokuma, J. Chem. Phys., 1971, 55, 1236-1244.

42 H. M. von and G. Frenking, Comput. Mol. Sci., 2012, 2, 43-62.

43 T. Ziegler and A. Rauk, Theor. Chem. Acc., 1977, 46, 1-10.

44 S. I. Gorelsky, S. Ghosh and E. I. Solomon, J. Am. Chem. Soc., 2006, 128, 278-290.

45 S. I. Gorelsky, AOMIX, Department of Chemistry, York University, Toronto, ON, http://www.sg-chem.net, 2011.

46 S. I. Gorelsky and A. B. P. Lever, J. Organomet. Chem., 2001, 635, 187-196.

47 C. E. MacBeth, R. Gupta, K. R. Mitchell-Koch, V. G. Young, G. H. Lushington, W. H. Thompson, M. P. Hendrich and A. S. Borovik, J. Am. Chem. Soc., 2004, 126, 2556-2567.

48 R. Gupta, C. E. MacBeth, V. G. Young and A. S. Borovik, J. Am. Chem. Soc., 2002, 124, 1136-1137.

49 D. C. Lacy, J. Mukherjee, R. L. Lucas, V. W. Day and A. S. Borovik, Polyhedron, 2013, 52, 261-267.

50 Z. Shirin, V. G. Young Jr. and A. S. Borovik, Chem. Commun., 1997, 1967-1968.

51 Z. Shirin, B. S. Hammes, V. G. Young and A. S. Borovik, J. Am. Chem. Soc., 2000, 122, 1836-1837.

52 R. L. Shook, S. M. Peterson, J. Greaves, C. Moore, A. L. Rheingold and A. S. Borovik, J. Am. Chem. Soc., 2011, 133, 5810-5817. 
53 R. Latifi, M. A. Sainna, E. V. Rybak-Akimova and S. P. de Visser, Chem.-Eur. J., 2013, 19, 4058-4068.

54 A. S. Borovik, Acc. Chem. Res., 2005, 38, 54-61.

55 T. H. Parsell, R. K. Behan, M. T. Green, M. P. Hendrich and A. S. Borovik, J. Am. Chem. Soc., 2006, 128, 8728-8729.

56 C. E. MacBeth, R. Gupta, K. R. Mitchell-Koch, V. G. Young Jr., G. H. Lushington, W. H. Thompson, M. P. Hendrich and A. S. Borovik, J. Am. Chem. Soc., 2004, 126, 2556-2567.

57 A. Dey, R. K. Hocking, P. Larsen, A. S. Borovik, K. O. Hodgson, B. Hedman and E. I. Solomon, J. Am. Chem. Soc., 2006, 128, 9825-9833.

58 J. F. Hull, D. Balcells, E. L. O. Sauer, C. Raynaud, G. W. Brudvig, R. H. Crabtree and O. Eisenstein, J. Am. Chem. Soc., 2010, 132, 7605-7616.

59 K.-B. Cho, S. Shaik and W. Nam, J. Phys. Chem. Lett., 2012, 3, 2851-2856.
60 C. Li, D. Danovich and S. Shaik, Chem. Sci., 2012, 3, 19031918.

61 (a) D. Janardanan, Y. Wang, P. Schyman, L. Que Jr. and S. Shaik, Angew. Chem., Int. Ed., 2010, 49, 3342-3345; (b) R. Latifi, L. Tahsini, B. Karamzadeh, N. Safari, W. Nam and S. P. de Visser, Arch. Biochem. Biophys., 2011, 507, 4-13; (c) A. Ansari, A. Kaushik and G. Rajaraman, J. Am. Chem. Soc., 2013, 135, 4235-4249; (d) M. Jaccob and G. Rajaraman, Dalton Trans., 2012, 41, 10430-10439.

62 (a) J. J. Warren, T. A. Tronic and J. M. Mayer, Chem. Rev., 2010, 110, 6961-7001; (b) T. J. Meyer, M. H. V. Huynh and H. H. Thorp, Angew. Chem., Int. Ed., 2007, 46, 5284-5304; (c) D. R. Weinberg, C. J. Gagliardi, J. F. Hull, C. F. Murphy, C. A. Kent, B. C. Westlake, A. Paul, D. H. Ess, D. G. McCafferty and T. J. Meyer, Chem. Rev., 2012, 112, 4016-4093. 